\title{
11 Delimiting and Justifying Protection under the ECHR
}

WHILE THE PRECEDING CHAPTER answered some questions on the protective capacities of international law, it at the same time raised new and ever more complex ones. We came to the conclusion that the CAT, the ICCPR and the ECHR all contained norms prohibiting refoulement. While the protective ambit of CAT was rather clear cut-Article 3 was the sole provision impacting removal of aliens, and it covered removal to torture only-both the ICCPR and the ECHR proved trickier to delimit. As a comprehensive interpretation based on the Vienna Convention has shown, we must endorse that Article 7 ICCPR and Article 3 ECHR protect from removal and entitle to access at the border. Most intriguingly, it emerged that Article 3 ECHR also contained an implicit right to access from other territories.

At this juncture, then, the question imposes itself whether other provisions of the ICCPR and the ECHR unfold corresponding effects. Does the right to a fair trial contain an implicit prohibition of refoulement? If one accepts the implications of the prohibition of illtreatment upon removal, must one not also endorse parallel implications of the right to life? In the case of the ECHR, the consequences would attain a revolutionary tinge. If there is a right to access for persons 
threatened with torture in a third country, there might also be a right to access for persons whose right to free speech is impaired. Affirming that all rights in the ECHR and its Protocols can be transformed into ancillary rights to non-refoulement would potentially undermine large parts of current migration control policies in Furope.

This suggests that future battles on the extent of extraterritorial protection are to be fought in the arena provided by the ECHR and that their intensity will exceed those on the 1951 Refugee Convention. After all, a potentially much broader protection package is at stake, coupled with a rather impressive inherent right to access. The deliberations on subsidiary protection within the Council represent only feeble preliminaries for things to come. ${ }^{1290}$ Let us anticipate this discussion in the present chapter, which is fuelled by two questions. Where exactly are the boundaries of extraterritorial protection under the ECHR? How are these boundaries justified? We shall look into responses developed in the case law of the European organs and by doctrinal writers. Given that the ECHR possesses a more powerful monitoring mechanism than the ICCPR and comprises an implied right to access as well, we shall limit our scrutiny to the former. Suffice it to note that the delimitation of extraterritorial protection and its justification under both instruments is largely parallel.

\subsection{The Case Law of the European Organs}

Do all human rights listed in Section I of the ECHR contain an implicit prohibition of refoulement? In Soering, the European Court has made clear that extraterritorial protection need not be confined to Article 3 ECHR when stating that in so far as a measure of extradition has

1290 The Council seems to be at pains to realise the impact of the ECHR on extraterritorial protection. While it is laudable that a structured discussion on subsidiary protection has started, and that the Amsterdam Treaty has created legal competencies for an EC measure on the topic, the Council's General Secretariat appears to have difficulty realising the full impact of the ECHR on extraterritorial protection. In the Council's study on subsidiary protection, the issue of non-refoulement under other provisions than Art. 3 ECHR is not even named. Furthermore, the study suggests 'it would [...] be wrong to assume that Article 3 would require Contracting States to adjust their admission policies'. For the reasons outlined in the preceding chapter, this suggestion is untenable. Council of the European Union, Study on international instruments relevant to subsidiary protection, 13 July 1998, Doc. No. 10175/98 ASIM 178, p. 8. 
consequences adversely affecting the enjoyment of a Convention right, it may, assuming that the consequences are not too remote, attract the obligations of a Contracting State under the relevant Convention guarantee'. ${ }^{1291}$ The case law of the European organs provides a few indications on the potential of other provisions than Article 3 ECHR with regard to extraterritorial protection. The right to life, the prohibition of the death penalty, the right to a fair trial and the right to family life have been expressly addressed by the European organs in a context of non-refoulement. In the past, the latter have not had the opportunity to pronounce themselves on the inherence of nonrefoulement in other rights than those named. Let us embark on a brief overview.

Concerning the right to life, the Commission has explicitly stated that removal of a person to a state where his or her life is endangered may engage responsibility under Article $2 \mathrm{ECHR}$, prohibiting the intentional deprivation of life. ${ }^{1292}$ Precisely as is the case with Article 3 ECHR, Article 2 ECHR does not allow for exceptions and cannot be derogated from in time of war or other public emergency. However, the provisions differ in that Article $2 \mathrm{ECHR}$ contains a requirement of intent, while Article 3 ECHR does not. Accordingly, when seized with an issue under Article 2 ECHR, the Commission applied a far more exigent standard of proof than under cases related to Article 3 ECHR:

As to the prohibition of intentional deprivation of life, the Commission does not exclude that an issue might be raised under Article 2 in circumstances in which the expelling State knowingly puts the person concerned at such high risk of losing his life as for the outcome to be a near-certainty. The Commission considers, however, that a "real risk"-within the meaning of the case-law concerning Article 3 [...] -of loss of life would not as such

1291 Soering, para. 85.

1292 Application No. 25894/94, Babaddar vs. the Netherlands, Report by the Commission of 13 September 1996, para. 78. Application No. 14912/89, X vs Switzerland (unpublished), quoted in W. Kälin, Die Bedeutung der EMRK für Asylsuchende und Flüchtlinge. Materialien und Hinweise (1997, ZDWF, Bonn), p. 19. 


\section{CHAPTER 11}

necessarily suffice to make expulsion an "intentional deprivation of life" prohibited by Article 2, although it would amount to inhuman treatment within the meaning of Article $3 .{ }^{1293}$

In practice, though, this need not diminish the protective scope of the ECHR. As the Commission suggests in the last words of the quoted passage, a threat not satisfying the requirements of Article 2 ECHR may very well fall under the protective ambit of Article 3 ECHR. ${ }^{1294}$

The prohibition of condemning a person to the death penalty or executing her contained in Article 1 of the Sixth Additional Protocol of the ECHR $^{1295}$ could also contain an inherent prohibition of nonrefoulement. In Soering, the ECtHR was inhibited to pursue this question further, as the respondent state was not bound by the Protocol. ${ }^{1296}$ The European Commission has considered extraterritorial protection under Article 1 of the Protocol as arguable in $Y$ vs. the Netherlands without however providing further details. ${ }^{1297}$

Concerning the right to fair trial, the European Court 'does not exclude that an issue might exceptionally be raised under Article 6 by an

1293 Application No. 25894/94, Bahaddar vs. the Netherlands, Report by the Commission of 13 September 1996, para. 78.

1294 We note, however, that the requirement of proof under Article 2 ECHR, as expressed in the previously quoted case of the European Commission, is higher than the corresponding demands in Art. 5 of the Principles on the effective prevention and investigation of extra-legal, arbitrary and summary executions. The latter provision reads: 'No one shall be involuntarily returned or extradited to a country where there are substantial grounds for believing that he or she may become a victim of extra-legal, arbitrary or summary execution in that country'. To be sure, the word 'may' sets a lower threshold of proof than the term 'real risk', which is used by the European Commission. It is most unfortunate that a regional human rights mechanism features a lower degree of protection than what has been politically consented upon at the universal level. Fully conscious of the non-binding character of the Principles as such, the observer wonders why the European Commission has felt the need to amplify this difference by introducing the very demanding concept of 'near-certainty'. Principles on the effective prevention and investigation of extra-legal, arbitrary and summary executions, recommended by Economic and Social Council resolution 1989/65, 24 May 1989.

1295 Protocol No. 6 to the European Convention for the Protection of Human Rights and Fundamental Freedoms concerning the Abolition of Death Penalty, Strasbourg, 28 April 1983, E.T.S. 114.

1296 Soering, paras 102 and 103.

$1297 Y$ vs the Netherlands, Decision of 16 January 1991, Appl. No. 16531/1990, Decisions and Reports 68 (1991), para. 304. 
extradition decision in circumstances where the fugitive has suffered or risks suffering a flagrant denial of a fair trial in the requesting country'. ${ }^{1298}$ This position was reiterated by the Commission in the Kozlov case. ${ }^{1299}$ Parenthetically, it might be of some interest to note that the right to fair trial figures also amongst the mandatory grounds for refusal of extradition named in Article 3 of the UN Model Treaty on Extradition. ${ }^{1300}$

With regard to the right to family life, we must distinguish those cases where family life on the territory of the removing party is disrupted from those where a disruption takes place extraterritorially. True to the delimitation of this work to extraterritorial protection, only the latter cases are of interest. ${ }^{1301}$ In Cruz Varas, the European Court has shown itself prepared to scrutinise whether a disruption of family life due to removal and outside the territory of the respondent state violates Article 8 ECHR. ${ }^{1302}$ This implies that, in the Court's view, Article 8 ECHR also features an inherent prohibition of refoulement.

Although it has proved willing to embrace other provisions than Article $3 \mathrm{ECHR}$, the Court has been far from making itself a harbinger of universalism. As earlier noted, it has stressed the exceptional character of extraterritorial protection under the Convention. It has underscored that

1298 Soering, para. 113.

1299 Kozlov vs Finland, Decision of 28 May 1991, Appl. No. 16832/1990, Decisions and Reports 69 (1991), para. 332.

1300 This provision reads as follows:

'Extradition shall not be granted in any of the following circumstances:

$[\ldots]$

(f) $[\ldots]$ if that person has not received or would not receive the minimum guarantees in criminal proceedings, as contained in the International Covenant on Civil and Political Rights, article 14;

(g) If the judgement of the requesting State has been rendered in absentia, the convicted person has not had sufficient notice of the trial or the opportunity to arrange for his or her defence and he has not had or will not have the opportunity to have the case retried in his or her presence.'

G.A. Res. 45/116, Model Treaty on Extradition, 14 Dec. 1990, UN Doc. No. A/RES/45/116. While not binding as such, this instrument might be of some use when analysing the opinio juris with regard to the permissibility of extradition under customary international law. As stated earlier, an analogy can be drawn to removal other than extradition.

${ }^{1301}$ For a general overview on the case law related to removal and Article 8 ECHR, see A. Sherlock, 'Deportation of Aliens and Article 8 ECHR', 23 European Law Review (1998).

1302 Cruz Varas, para. 88. 


\section{CHAPTER 11}

its Article 1 'cannot be read as justifying a general principle to the effect that, notwithstanding its extradition obligations, a Contracting State may not surrender an individual unless satisfied that the conditions awaiting him in the country of destination are in full accord with each of the safeguards of the Convention'. ${ }^{1303}$ At face value, this allows for three possible readings. First, there are some Convention rights which do not unfold extraterritorial protection. Or, second, in an extraterritorial context, the protection through each Convention right is not as far reaching as in the domestic context. Or, thirdly, both limitations could apply. Seemingly, the Court discards the fourth option, and therewith the congruency of extraterritorial and domestic protection under the ECHR.

Anything else than the fourth option requires that a line be drawn. This line is differently located in the first and the second reading. While the first reading implies a hierarchy among the rights in Section I of the ECHR, the second implies a hierarchy within these rights. According to the first reading, some rights are 'superior' to others, motivating and justifying their potential for extraterritorial protection. ${ }^{1304}$ Following the second reading, some violations of a right are superior to others, which motivates and justifies that extraterritorial protection be granted for the former. When browsing through relevant doctrinal text in the following, we shall see how the argumentative patterns of both readings resurfacetracking either which rights apply, or to what extent they apply to extraterritorial protection.

\subsection{A Hierarchy among Rights?}

Let us start out with the first reading and, hence, with which rights apply. Close to the particularist end of the spectrum, we find a position that argues that extraterritorial protection under the ECHR is exclusively confined to Article 3 ECHR. ${ }^{1305}$ Another, less rigidly formulated, but materially identical, approach accords Article $3 \mathrm{ECHR}$ the function of a passerelle to extraterritorial protection. The latter position can be

\footnotetext{
1303 Soering, para. 86.

1304 Zühlke and Pastille, 1999 have provided an excellent overview of a broad variety of superiority arguments, discarding them in a systematic fashion.

${ }^{1305}$ See A. H. Robertson and J. G. Merrills, Human Rights in Europe (1993, Manchester University Press, Manchester), p. 44.
} 
exemplified with the case of a person threatened with an unfair trial in her home country. Removal to that country would be considered inhuman treatment and would thus violate Article 3 ECHR, rather than Article 6 ECHR. The bottom line is that the feared treatment must qualify as inhuman in the sense of Article 3 ECHR. Proponents of the latter position ${ }^{1306}$ appear to have been inspired by the earlier case law of the European Commission ${ }^{1307}$-case law that is obsolete after Soering and the cases referred to earlier in this sub-section. ${ }^{1308}$

Taking any of these limitative positions inevitably leads one to ask why the prohibition of ill-treatment in Article 3 ECHR should enjoy special status among the rights enshrined in the ECHR and its Protocols. As noted in doctrine, "[i]t remains unclear where the superiority of Article 3 is located'. ${ }^{1309}$ Arguing for a special character of torture-related norms, motivating their exclusive possession of extraterritorial range, is indeed a demanding task. It is by no means evident why protection from torture is tantamount to protection from other 'irremediable damages' such as, for example, the intentional deprivation of life. Neither the wording, nor the context, nor the telos of Article 3 ECHR accommodate an exclusive possession of non-refoulement capacities. Nor can the absence of permissible limitations in Article 3 ECHR and its non-derogable character support hierarchical superiority within Section I-after all, both characteristics are shared by other provisions of the ECHR. As a result, we must reject the two limitative approaches.

What then is the criterion singling out a special class of rights endowed with an inherent prohibition of refoulement? This criterion can be sought either within the text of the ECHR or outside it.

Taking the latter approach, a distinct effort to argue for the special status of Article 3 ECHR was made in 1988 by Vogler, who advances a jus cogens-criterion. He contends that Article 3 ECHR inhibits extradition,

1306 Accounting for arguments in favour of such an exclusive possession, Maaßen, 1997, p. 136, states that the European organs ultimately focus on the legality of removal from the sending state and not the legality of the presumed treatment in the receiving state. But see Zimmermann, 1994, p. 90 f, Suntinger, 1996, p. 214, affirming an independent prohibition of refoulement under Art. 2 ECHR.

1307 Zühlke and Pastille, 1999, pp. 756-7.

${ }^{1308}$ The reader will note that both limitative positions are at odds with the Court's own position, as stated earlier. See text accompanying note 1291 above.

1309 Zühlke and Pastille, 1999, p. 757. 


\section{CHAPTER 11}

while Article 6 ECHR does not. ${ }^{1310} \mathrm{He}$ bases this contention on the observation that only Article $3 \mathrm{ECHR}$ represents a 'general rule of international law recognised by civilised nations' in its totality, while, for example, the principles of legality of procedure enshrined in Article 6 ECHR 'belong to them only in their intrinsic components'. $1311 \mathrm{He}$ elevates this conclusion to a general theory: '[w] hether a State is allowed to extradite [...] ultimately depends on the classification of rules as belonging to the international ius cogens'. ${ }^{1312}$

Van Dijk refutes this argumentation with a reference to the competence of the Strasbourg organs, which is limited to the "engagements undertaken by the High Contracting Parties in the present Convention"1313. This misses the point, as Vogler uses the criterion of jus cogens only to single out those norms in the ECHR endowed with an inherent non-refoulement capacity. The responsibility of State Parties to the ECHR is still based directly on the ECHR, which is merely interpreted in the light of international law.

Other reasons militate against Vogler's explanation, which is ultimately an attempt to craft an argument capable of superseding contractual obligations under bi- or multilateral extradition agreements. ${ }^{1314}$ Vogler

1310 This was roughly a year before the ECtHR spelt out in Soering that Art. 6 ECHR could very well provide a basis for extraterritorial protection. See text accompanying note 1298 above.

1311 T. Vogler, 'The scope of extradition in the light of the European Convention on Human Rights', in F. Matscher and H. Petzold (eds), Protecting Human Rights: The European Dimension (Essays in Honour of G.J. Wiarda) (1988, Heymann. Köln), p. 669.

1312 Ibid., p. 670.

1313 P. van Dijk, Asylum Law and Policy in the Netherlands. The Dynamic of the Protection of Human Rights in Europe. Essays in Honour of Henry G. Schermers, Vol. III (1994, Martinus Nijhoff Publishers, Dordrecht), p. 139.

1314 Such agreements usually do not exempt persons risking torture or other forms of illtreatment in the requesting country from extradition obligations. It would follow e contrario from Vogler's approach that a State Party to the ECHR could liberate itself from its obligations vis-à-vis an individual under its jurisdiction by entering into a bilateral agreement to that effect with another state. This is clearly not the case, and one need not resort to jus cogens or, for that matter, obligations erga omnes to explain why. The answer lies in the fact that human rights are not a bilateral business with states as reciprocal beneficiaries. By agreeing to Article 1 ECHR, states have simply bound themselves not to enter such rights-impairing agreements. Otherwise put, Section 1 of the ECHR would constitute lex specialis in relation to extradition agreements. An interesting parallel is the explicit exemption of treaty provisions relating to the 'protection of the human person' from the party's disposal in Art. 60 (5) VTC. The 
meets this challenge by declaring Article $3 \mathrm{ECHR}$ to reflect a norm of higher dignity. ${ }^{1315}$ In the absence of rudimentary forms of support from the actors of international law, the qualification of norms as peremptory is still a disturbingly controversial affair. ${ }^{1316}$ Zühlke and Pastille have aptly demonstrated the practical fallacy of reasoning based on jus cogens by comparing two cases involving the death row phenomenon. In Soering, the ECtHR considered the death row phenomenon to constitute inhuman treatment in the sense of Article 3 ECHR. In Kindler, however, the Human Rights Committee did precisely the opposite. ${ }^{1317}$ It is little helpful to declare a norm to be jus cogens, when there is such disagreement on its content by highly qualified actors as the ECtHR and the HRC. Similar reflections apply to an approach based on obligations erga omnes ${ }^{1318}$ or on attempts to identify a group of basic protection norms in international treaty law ${ }^{1319}$. Therefore, we are compelled to conclude that these concepts are of no help when identifying the rights in Section I ECHR or in the Protocols that may entail extraterritorial protection.

Let us now turn to the search for a criterion distinguishing such rights within the text of the ECHR. In 1982, Kälin proposed that nonrefoulement under the ECHR is reserved for violations of non-derogable rights as defined by Article $15 \mathrm{ECHR}$ and for the 'core content' ('Kerngehali') of other rights enshrined in the ECHR. ${ }^{1320}$ Regarding nonderogable rights, Ermacora agrees with Kälin: 'The most legal approach to the problem may be to state wherever rights might be involved which are even guaranteed in the case of public emergency (Articles 2, 3, $4 \$ 1$ and 7 of the Convention) a member State may be considered responsible under the Convention for actions taken with a view to deportation or

problem is that Article $1 \mathrm{ECHR}$ stretches over the whole rights catalogue contained in Section 1 of the ECHR. The contractual approach leads either to disturbing consequences for the international law of human rights or back to the original question.

1315 See Art. 59 VTC.

1316 A topical discussion with further references can be found with Higgins, 1993, pp. 20-2.

1317 Kindler revolved around whether the removal of the applicant to the U.S. would constitute a violation of Article 7 ICCPR. The HRC denied that a placement in death row would constitute inhuman treatment in the sense of Article 7 ICCPR. Kindler vs. Canada, para. 6.4. See Zühlke and Pastille, 1999, p. 765.

1318 For a good argumentation, see Zühlke and Pastille, 1999, p. 763.

1319 Zühlke and Pastille, 1999, p. 763.

1320 Kälin, 1982, pp. 181-2. 


\section{CHAPTER 11}

extradition'. ${ }^{1321}$ A delimitation turning on derogability appears to be plausible, as it follows a structure erected within the ECHR by the Contracting Parties themselves. The same would go for a delimitation based on which rights are formulated as 'absolute', that is, making no room for limitations. Such 'absolute' rights would offer protection from refoulement, while the 'relative' rights in Articles 8 to 11 would not. In its case law, the Court has repeatedly stressed the absolute nature of Article 3 ECHR as well as its non-derogability.

But this plausibility is deceptive. As Zühlke and Pastille have convincingly argued, it rests on a tautology: '[t]racing superiority with the help of non-derogable rights dwells on the assumption that those rights are non-derogable because they are superior-a classic circular argument'. ${ }^{1322}$ This works against all attempts to deduce a hierarchical structure from the textual manifestations and delimitations of rights, whether they be drawn from express limitations (as in Article 5 ECHR), justifiable interferences (Articles 8 to $11 \mathrm{ECHR}$ ) or derogability in case of public emergency (all rights other than those enshrined in Articles 2, 3, 4 (1) and 7 ECHR). Basically, the Convention text is no more than a structure of technical solutions to the problem of formulating rights with sufficient precision. There is no indication whatsoever that the chosen technical solutions are signs of superiority. ${ }^{1323}$

Further, the adequacy of terming rights as 'absolute' can be drawn into question. Along the terms suggested by Alan Gewirth, the absoluteness of a right implies that it survives a conflict with another right. ${ }^{1324}$ It is questionable, though, whether Article $3 \mathrm{ECHR}$, or, for that matter, similarly formulated rights in Section $I$, are absolute. As Zühlke and Pastille have argued, the precise extent of Article 3 ECHR cannot be established but on a case-by-case basis, necessitating subjective assessments

\footnotetext{
${ }^{1321}$ F. Ermacora, 'The Application of the ECHR in Asylum Cases', in R. Lawson and M. de Blois (eds), The Dynamic of the Protection of Human Rights in Europe. Essays in Honour of Henry G. Schermers. Vol. III (1994, Martinus Nijhoff Publishers, Dordrecht), p. 162.

${ }^{1322}$ Zühlke and Pastille, 1999, p. 761.

1323 'The different mechanics of protecting rights follow substantial differences in the history and practical nature of those rights. The different forms that rights take in the Convention cannot serve as an indicator of superiority [footnote omitted, GN].' Zühlke and Pastille, 1999, p. 760.

1324 Addo and Grief, 1998, p. 514, quoting A. Gewirth, Human Rights. Essays on Justification and Applications (1982, University of Chicago Press, Chicago/London), p. 219.
} 
by means of a weighing process. ${ }^{1325}$ Consider two police officers marching a handcuffed and sparsely clad person over a public square. Whether or not this is degrading treatment in the sense of Article 3 ECHR depends on the circumstances. Provided that person is a suicide assassin, such conduct is likely to be justified. Where the same person has merely committed a minor traffic offence, this public display would most certainly be considered degrading by the European Court. ${ }^{1326}$ Thus, Addo and Grief are certainly right when stating that the case law 'gives an impression of shifting boundaries as regards the character and scope of the absolute nature of the prohibitions in Article 3, ${ }^{1327}$ Where the fringes of a right are dynamic to this degree, what sense does it make to suggest that it survives a conflict with any other right? The example has shown that the rights of others-e.g. the potential victims of a suicide assassin-impact on the extent of the right enjoyed by the person marched over the public square. What one could validly claim is that a core content of Article 3 ECHR (e.g. the more specific concept of torture) will always survive and is thus absolute. ${ }^{1328}$ But this is true for any of the rights in Section I-beyond justified interference and the margin of appreciation. So, in the end, there is no difference between Article 3 ECHR, and, say, Article 8 ECHR. At the fringes of Article 3 ECHR, the concept of absoluteness turns out to be materially empty. ${ }^{1329}$ Thus, it is useless for discerning hierarchical structures among the single rights enshrined in Section I ECHR. ${ }^{1330}$ Hence, we can discard the first reading of the European Court's dictum quoted earlier.

\footnotetext{
1325 Zühlke and Pastille, 1999, pp. 770-2.

1326 The example is taken from Zühlke and Pastille, 1999, p. 771.

1327 Addo and Grief, 1998, p. 514.

${ }^{1328}$ However, while the torture concept may represent a 'core content' for Art. 3 ECHR, the same is not true for Art. 3 CAT, where the fringes of the concept are highly contested grounds. This is so because the buffer zone of other forms of ill-treatment is unavailable under the latter provision.

1329 It is no coincidence that Gewirth, while affirming the existence of absolute moral rights, chooses to formulate them in very abstract terms. Gewirth illustrates rule absolutism by the right not to be made the intended victim of a homicidal project, and principle absolutism by the principle that agents and institutions are absolutely prohibited from degrading persons, treating them as if they had no rights or dignity. Gewirth, 1982, p. 233.

1330 By stating this, we have taken no position on the existence of absolute rights.
} 


\section{CHAPTER 11}

This brings us back the second part of Kälin's proposal, turning on the notion of a 'core content' inherent in each right. Kälin himself defines the concept of core content as the realm of a right, which cannot be infringed upon without eradicating the right as such. ${ }^{1331}$ Indeed, it is not simple to make Kälin's formula operational right away. Two alternative understandings are conceivable. Either Kälin wishes to separate violations of the core content from less severe violations, with only the former entailing extraterritorial protection, or any infringement into a derogable right beyond what has been termed the margin of appreciation would be regarded as touching upon the core content. This reading would make Kälin's proposal congruent with the fourth reading, affirming the congruence of extraterritorial and domestic protection under the ECHR. Consequently, it is reasonable to assume that Kälin indeed had the first alternative in mind when formulating himself.

Using the notion of a 'core content' implies erecting a hierarchy within a right. It is of little surprise that Kälin's usage of the notion has been met with criticism for its ambiguity. ${ }^{1332}$ Thus, the search must go on. Exactly how shall the line be drawn between the core content and the fringes of the rights enshrined in Section I? In the following, we shall test a delimitative criterion inferred from the case-law of the European organs.

\subsection{Irreparability as a Water-Shed?}

The European Court has stressed that it was only willing to rule on a potential violation of the ECHR due to the irreparable nature of damages flowing from removal to a country where there is a risk of treatment contrary to Article $3 \mathrm{ECHR} .{ }^{1333}$ Could the notion of irreparability be a water-shed, separating those violations triggering refoulement from those which do not? It is worth recalling that the instruments themselves do not spell out which violations are to be regarded as causing irreparable damages. Neither did the European organs give further guidance on the

1331 The doctrine of core content is highly relevant in a constitutional context. As an example, the German legislator may very well change single provisions in the rights catalogue of the German Constitution, as long as the core content of the right to human dignity remains unaltered. Art. 79 (3) of the German Basic Law (Grundgesetz).

1332 Gornig, 1987, pp. 33-4, Maaßen, 1997, pp. 130-1.

1333 Soering, para. 90. 
issue of reparability. Nonetheless, the concept of irreparability fits well together with the subsidiary character of extraterritorial human rights protection.

Which human rights violation could qualify as irreparable? Tentatively, one could to distinguish three main categories of violations. The first category comprises violations leading to a direct or indirect termination of life. Starting with a truism, one can state that the intentional deprivation of life is an irreparable violation. ${ }^{1334}$ From this, it can be inferred that violations of due process ${ }^{1335}$ and the maxim of nullum crimen sine lege $e^{1336}$ fall into the same category, if conviction would result in capital punishment.

The second and third categories encompass violations that are not irreparable per se, as a violation would not lead to a termination of the victim's life. However, amongst those rights, two additional factors might endow a violation with irreversibility: therapy-resistant traumatisation and lack of legal remedies. This category is made up of right violations other than those falling under the first category.

In certain cases, violations of human rights falling short of a direct or indirect deprivation of life can nevertheless lead to a trauma for the victim, which is resistant to therapy. Such a trauma becomes irreversible in the sense that the violation continues to affect the mental or physical health of the victim. Thus, the violation is perpetuated. Clearly, violations of Article 3 ECHR are cases in point. Torture is highly traumatising and affects the victim over a long period, if not the rest of his or her life. ${ }^{1337}$ In specific cases, the same might be true for violations of other human rights, depending on the gravity of the violation and its effects for the individual victim. In other words, the risk assessment carried out before a removal decision must comprise an individual evaluation of possible traumatisation by the violation of any human right, which the sending state is obliged to observe.

\footnotetext{
1334 Art. 2 ECHR and Art. 1 of the Sixth Protocol respectively.

1335 Art. 6 ECHR.

1336 Art. 7 ECHR.

${ }^{1337}$ In a lucid essay recounting his repeated interrogation by SS agents in 1943, Jean Améry has condensed the impact of torture when stating 'Wer gefoltert wurde, bleibt gefoltert' (He, who has been tortured, remains tortured). J. Améry, Jenseits von Schuld und Sühne. Bewältigungsversuche eines Überwältigten, July 1988 ed. (1988, Deutscher Taschenbuch Verlag/Klett-Cotta, Sturtgart), p. 51.
} 


\section{CHAPTER 11}

Apart from cases falling under the second category, violations can also be perpetuated by the absence of a legal remedy ending rights-violating practices. This constitutes the third category of violations. Let us assume that a person is arbitrarily detained. In the absence of legal remedies, such detention cannot be subjected to legal scrutiny. There are no means of putting a stop to the denial of human rights in such cases, which constitutes a violation of its own right according to Article $13 \mathrm{ECHR}$. Accordingly, the absence of legal remedies makes a violation practically irreversible and, consequently, irreparable.

The criterion of irreparability would thus establish a hierarchy both among and between rights. Along the lines suggested above, the concept of irreparability could be made the cornerstone of a doctrine of extraterritorial protection under the ECHR. Its central proposition might be formulated as follows: All human rights enshrined in the ECHR and its Protocols contain an inherent prohibition of refoulement to a country where there is a risk of an irreparable human rights violation. A violation is irreparable inter alia when it directly or indirectly terminates the life of the victim, when it produces a trauma resistant to therapy or when there are no legal remedies available to redress the violation.

But the concept of irreparability is burdened with problems. Precisely like the notion of a 'core content' of human rights, it is ambiguous and difficult to pin down: we may all agree that torture is irreparable, but we are not so sure when it comes to degrading treatment. Thus, the concept of irreparability opens up a new arena for indeterminacy, turning on the question of exactly what is reparable and what is not. Furthermore, the distance of this notion to the letter of the ECHR is considerable: we have inferred this rule from the case law of the European organs, which, in turn, is based on the letter of the law. That adds up to three steps, and a considerable degree of abstraction. This inherent abstraction produces unrestrained conflicts on a meta-legal level: instead of being based on the law, the decisive arguments will be medical, psychological, or otherwise technical. In addition, it is hard to justify the water-shed of irreparability within the normative edifice of the ECHR itself. There are no indications that its drafters intended to create a hierarchy of violations according to reparability. Dogmatically, the determination of non-refoulement obligations by a criterion of irreparability would simply not fit into the framework of the ECHR. Although the question of reparability remains an important factor when assessing the severity of a certain treatment 
alleged to violate the ECHR, it alone cannot serve as the water-shed we are tasked with identifying here.

\subsection{A Hierarchy within Rights: The Concept of Positive Obligations}

At this stage, it appears that no simple and objective criterion can be found which would determine non-refoulement obligations under the ECHR and its Protocols. We seem to be stuck with a case-by-case approach, necessitating subjective evaluations by the decision-maker. Indeed, Zühlke and Pastille have suggested that, in the absence of a predetermined superiority of certain rights, all rights are principally capable of possessing non-refoulement properties. ${ }^{1338}$ However, the extent to which they do so is to be determined by a 'direct balancing' of the interests of the persons to be removed against those of the removing state. ${ }^{1339}$ In justifying this approach, the authors draw a parallel to inhuman or degrading treatment or punishment under Article 3 ECHRthe existence of which is, in their view, established by balancing state interests against those of the individual.

Seconding Zühlke and Pastille, we would like to underscore that this balancing is not the same as the one proposed by the Chabal dissenters. While the latter wished to balance an established violation of an ECHR right against state interests, Zühlke and Pastille resort to balancing only to establish whether an ECHR right would be violated at all. It is quite obvious that the option proposed by the Chabal dissenters doubles the degree of discretion-balancing is applied both to establish the existence of a violation, and its permissibility. This is at odds with Article $15 \mathrm{ECHR}$, which is exhaustive with regard to additional powers of limitation. ${ }^{1340}$

By and large, to describe the establishment of non-refoulement rights as a balancing process has a great deal of merit. Indeed, when confronted with the fringe areas of rights, we agree that there is a predominantly subjective and case-oriented element in singling out the extent of protection by them. However, while the 'direct balancing approach' is reflective of the European organs' practice, it is incapable of justifying it.

\footnotetext{
1338 Zühlke and Pastille, 1999, p. 766.

1339 Zühlke and Pastille, 1999, p. 769.

1340 Zühlke and Pastille, 1999, p. 769.
} 


\section{CHAPTER 11}

Below, we shall attempt to develop a dogmatically more coherent approach, drawing on the concept of positive obligations. ${ }^{1341}$

We shall suggest a two-pronged procedure for identifying whether a specific threat in the country to which the claimant shall be removed entails extraterritorial protection under the ECHR or its Protocols. In the first step, one would ask

O Would one or more of the rights protected in Section I of the ECHR and the Protocols to the ECHR be violated upon removal?

In the first step, any violation of any right is of interest. To be sure, a discriminatory or non-emergency derogation of a derogable right would also be considered a violation. ${ }^{1342}$ In principle, the assessment of when a right is violated would not differ from that made in a purely domestic context. That is, the threat of ill-treatment by police officers in the home country of the claimant would be assessed in exactly the same manner as if that threat emanated in the host country where protection is sought. This is valid for all rights, regardless of whether or not they are derogable or may or may not be restricted under the ECHR. Thus, an alleged.violation of a right which may be subject to restrictions (Articles 8-11 ECHR) will also need to be assessed against the benchmarks provided in the second paragraph of each of these articles. To identify whether a restriction is acceptable under the named provisions, it must be lawful, serve a specified interest and be 'necessary in a democratic society'. To assess the latter benchmark, the alleged violation is subjected to the proportionality test developed by the European organs.

The qualification of the threat as a violation is a necessary criterion for triggering extra-territorial protection under the ECHR. However, it is not sufficient that this criterion is satisfied. If and only if a potential violation has been established in the first step, we shall proceed to the second. The second step turns on the following question:

Do the positive obligations flowing from that right impede removal?

\footnotetext{
${ }^{1341}$ On the logical structure of positive obligations, see R. Alexy, Theorie der Grundrechte (1985, Suhrkamp, Frankfurt am Main), pp. 179-94.

1342 Compare Arts 14 and 15 (1) ECHR.
} 
Why is such a step necessary? We recall that the European organs had focused on the obligations of the host state, and not of the country of origin, when justifying the implicit prohibition of refoulement under Article 3 ECHR. Undoubtedly, removal would be perfectly legal under the ECHR in situations where a person is removed from the territory of a host state and subsequently becomes the victim of unforeseeable violations; the responsibility of the removing state under the ECHR is not engaged in such cases. Obviously, we need to involve the issues of risk and predictability to clear our minds on the scope of extraterritorial protection under the ECHR.

To understand the necessity of risk assessments, we should revert to a purely domestic level for a moment. The positive obligations enshrined in Section 1 of the ECHR and its Protocols make such assessments by State Parties necessary on a regular basis. The right to life, for example, cannot be actively protected without clarifying which kinds of risks it is exposed to and what measures of protection are proportional to the probability linked to such risks. In a case turning on the legality of a vaccination scheme under Article 2 ECHR, the Commission reasoned as follows.

\begin{abstract}
The concept that everyone's life shall be protected by law "enjoins the State not only to refrain from taking life intentionally" but, further, to take appropriate steps to safeguard life. However in the present case the Commission is satisfied that, where a small number of fatalities occur in the context of a vaccination scheme, whose sole purpose is to protect the health of society by eliminating infectious diseases, it cannot be said that there has been an intentional deprivation of life within the meaning of Article 2 (1) or that the State has not taken adequate and appropriate steps to protect life. ${ }^{1343}$
\end{abstract}

Risk assessments are, however, not limited to those rights which are perceived as containing predominantly negative obligations, that is, the obligation to abstain from a certain conduct. The prohibition of inhuman treatment implies, for example, that a State Party analyses a certain planned action vis-à-vis an individual under its jurisdiction with a view to the severity of suffering it produces. In the absence of such a positive obligation to assess the conformity of future conduct under the ECHR,

${ }_{1343}$ Dec. Adm. Com. Ap. 7154/75, 12 July 1978, D \& R 14 p. 31, (32-3). 


\section{CHAPTER 11}

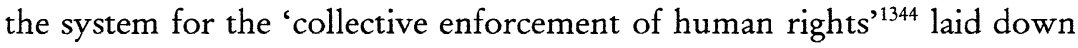
in that instrument would mainly rest on a 'trial and error' process.

A positive obligation-that is, in the case of Article 3 ECHR, an obligation to prevent ill-treatment-does have its reasonable limits. Such an obligation does not imply that a state has to take any conceivable measure to prevent ill-treatment. The process of choice involves with necessity considerations of risk, if the state's scarce protective resources should be used in an efficient manner. To illustrate this relationship, one might look at ill-treatment in the domestic sphere of a State Party to the ECHR. It is clearly a violation of Article 3 ECHR when state agents actively ill-treat a person. When state agents acquiesce to ill-treatment carried out by a third person, this is also regarded as a violation. However, the concept of acquiescence easily slips away into obscurity. Would it be acquiescence, and thus a violation of the ECHR, if the head of a municipal police department ordered downsizing of a district's resources, thereby accepting a higher rate of violent crime? It would not, if she could justify her decision with regard to crime rates in other, more violent districts and the scarcity of resources. Thus, in an effort to comply with the positive obligations flowing from the ECHR, she made a risk assessment to identify a measure providing an optimum of protection from violence.

Moving to an extraterritorial application of Article $3 \mathrm{ECHR}$, we find structural similarities. In both cases, violence would ultimately be exercised by non-state agents. In the preceding example, the agents would be criminals, and, in the case of refoulement, the agents would presumably be officials of another state. There is, however, state action that might aggravate or alleviate the risk of a violent incident. In the first example, such action would consist of the decision to downsize personnel in the police district. In the case of refoulement, it would be a decision of removal. To put it simply, a risk assessment translates the positive obligations abstractly inherent in a norm into concrete guidelines of action. Protection and predictability are interrelated: the more predictable a violation, the stronger becomes the protection claim of the presumptive victim.

A quite different question is the nature of such a risk assessment. In constant case-law, the European organs have stated that a violation of Article $3 \mathrm{ECHR}$ in a refoulement context presupposes that 'substantial

1344 Soering, para. 87 with further references. 
grounds have been shown for believing that the person concerned faces a real risk of being subjected to torture or to inhuman or degrading treatment or punishment in the country to which he or she was returned'. ${ }^{1345}$ The reader will note a triple threshold in this wording, the first regarding the probability of the risk, the second regarding the burden of proof and the third regarding the standard of proof. In the following, we shall focus on the dimension of risk.

First of all, the risk must be a real one, which indicates certain exigencies on the probability of its realisation. In the Soering case, the European Court has indicated that this probability need not be high. One commentator holds that any risk but a negligible one will do in cases related to Article $3 \mathrm{ECHR}^{1346}$; another has pointed to the proportionality between the risk requirements and the gravity of the anticipated violation. ${ }^{1347}$ We saw earlier that the requirement of intent in Article 2 ECHR entailed a risk approximating 'near-certainty'. As the requirement of risk varies between different provisions of the ECHR, it is important to analyse their wording before setting the yardstick for a risk assessment.

But when is the requirement of risk satisfied and the prohibition of refoulement triggered? This question can only be answered in a relative manner. Our reply draws on Alexy's principle theory, which understands human rights as 'commands of optimisation'. ${ }^{1348}$ In contradistinction to rules, principles command that something must be realised to a maximum extent in relation to legal and factual possibilities. In our context, the limitations lie first and foremost in factual possibilities. A host state is limited, first, in its capacity to foresee risks. To a certain degree, accuracy in prediction is a matter of invested resources. Beyond this degree, reality simply defies the most well funded auguries. Second, it cannot accept any risk whatsoever as a basis for non-refoulement, without undermining its resource base for human rights protection. Thus, in the assessment of the magnitude of the risk and the degree of predictability, the divide between

\footnotetext{
${ }^{1345}$ Nsona v. the Netherlands, para. 92, with further references.

1346 S. Egelund, "The Potential of the European Convention on Human Rights in Securing International Protection to Forcibly Displaced Persons', in UNHCR, The European Convention on Human Rights and the Protection of Refugees, Asylum-Seekers and Displaced Persons (1996, UNHCR, Geneva), p. 17.

1347 T. Einarsen, 'The European Convention of Human Rights and the Notion of an Implied Right to de facto Asylum' 2 IJRL 361 (1990), p. 371.

1348 Alexy, 1985, pp. 75 et seq.
} 


\section{CHAPTER 11}

universalism and particularism rears its head again. Although the subjectivity of weighing can be limited by the proper delimitation of discretion ${ }^{1349}$, a considerable degree of indeterminacy remains.

Let us revert to the possible readings of the European Court's dictum set out in the first section. We recall that the Court underlined that Article 1 ECHR 'cannot be read as justifying a general principle to the effect that, notwithstanding its extradition obligations, a Contracting State may not surrender an individual unless satisfied that the conditions awaiting him in the country of destination are in full accord with each of the safeguards of the Convention'. ${ }^{1350}$ In the course of our analysis, we had to discard the first reading, which assumed that there are some Convention rights which do not unfold extraterritorial protection. ${ }^{1351}$ What, then, about the second reading, professing that, in an extraterritorial context, the protection through each Convention right is not as far reaching as in the domestic context? Moreover, we have to ask whether the Court actually rules out the fourth option, and therewith the congruency of extraterritorial and domestic protection under the ECHR.

By now, we have to answer both questions in the negative. The extent of Convention protection is exactly as far reaching domestically as in an extraterritorial context, and, accordingly, both domains of protection are congruent. As the perpetrator of an act potentially violating the rights enjoyed under the ECHR is always a third party, and not the state from which protection is sought, extraterritorial protection is a matter of positive obligations only. By contrast, protection from violations within the territory of a State Party to the ECHR relates to both negative and positive obligations.

The notion of positive obligations facilitates our understanding of what the European Court actually meant in its dictum quoted above. As positive obligations have their limits, there cannot be a general principle to the effect that 'a Contracting State may not surrender an individual unless satisfied that the conditions awaiting him in the country of destination are in full accord with each of the safeguards of the Convention'. Clearly, there is no such principle in the domestic arena

\footnotetext{
${ }^{1349}$ For a model of weighing see, D. Herling, 'Weight in Discretionary Decision-Making', 19 Oxford Journal of Legal Studies (1999), drawing on the background of U.K. case law.

1350 Soering, para. 86.

1351 This invalidates automatically the third reading, professing that there is a hierarchy both among and within the rights enshrined in the ECHR and its Protocols.
} 
either-no State Party to the ECHR possesses the capacity to ensure conditions in its territory that are in full accord with each of the safeguards of the Convention. The term 'conditions' embraces not only conditions created by the state, which are fully subjected to the prescriptions of the ECHR, but also conditions that are not under the control of the state, which are therefore subject to the prescriptions of the ECHR only to the extent of the state's positive obligations.

\subsection{Conclusion}

Let us conclude. The European organs have opened up the ECHR for extraterritorial application without spelling out the theoretical foundations of their interpretation. This foundation can be reconstructed by focusing on the positive obligations flowing from the threatened right. Our model avoids imposing artificial hierarchies on the rights catalogue of the ECHR and is better apt to explain the language used in the decisions by the European organs. As we shall see in the following, the notion of positive obligations facilitates the analysis of extraterritorial protection by non-state agents of persecution as well. . $^{1352}$

However, to make this reconstruction operational for assessing future cases, we must accept a substantial amount of qualitative reasoning-and indeterminacy. In principle, any violation could entail eligibility for extraterritorial protection. Whether it actually will, depends on an in casu assessment, leaving much power to the decision-maker.

But this power is not unconstrained. The model expounded here offers the decision-maker a structure to follow. First, the extent of positive obligations under the invoked right has to be identified. As we saw earlier, not all provisions operate with the same threshold of risk exigencies. Second, it has to be determined whether the facts of the case fall within the extent of positive obligations. The facts of the case are a composite of two elements. The first relates to the degree to which the invoked right is violated upon return, while the second consists of the degree of predictability that this intrusion will materialise.

Opening up the ECHR for extraterritorial protection must certainly be regarded as a victory for universalism. However, as our model shows, it was a victory of the judge over the parliamentary legislator as well.

1352 See chapter 12.2 .2 .3 below. 


\section{CHAPTER 11}

Making the concept of positive obligations operational invests the decision-maker with considerable power; in this case, the decision-maker is, ultimately, the ECtHR. From now on, Strasbourg will hold the key to exclusion. This is not unproblematic for the universalist. After all, court majorities can change. What seems to be a victory for universalism in the ivory tower, can very well turn out to be its defeat in the courtroom one day. With a particularist majority amongst the judges, this concept may very well lead to regression in the scope of protection. 